\title{
Corpos, gêneros e subjetividades em disputa: reflexões a partir de um caso de violência em uma favela do Rio de Janeiro*
}

\author{
Paulo Victor Leite Lopes**
}

\section{Resumo}

A partir de uma situação de violência que envolveu um casal de jovens gays, alguns moradores e traficantes do Complexo da Maré, este artigo trata de dinâmicas concernentes à relação entre violência e subjetividade, tendo como horizonte de reflexão o debate acerca das formas de produção de corpos e gêneros. Ao incorporar o convite de W. Benjamin (2013) por uma "crítica da violência", tal fenômeno será tomado em seu caráter positivo, como um ato performático que produz corpos, moralidades $e$ gêneros naquele contexto. Por fim, corpos, moralidades, gêneros e a própria violência são compreendidos a partir de sua (re) elaboração através do contexto narrativo.

Palavras-chave: Corpos, Gêneros, Violências, Subjetividades, Narrativas.

* Recebido em 30 de maio de 2017, aceito em 18 de setembro de 2018.

** Professor Adjunto do Departamento de Antropologia e do Programa de PósGraduação em Antropologia Social da Universidade Federal do Rio Grande do Norte (UFRN), Natal, RN, Brasil. paulovleitelopes@gmail.com / https://orcid.org/0000-0001-9589-2248 
cadernos pagu (55), 2019:e195520 Corpos, gêneros e subjetividades em disputa

Bodies, Genders and Subjectivities in Dispute: Reflections on a violent event in a favela in Rio de Janeiro

\begin{abstract}
Beginning with a violent situation involving a young gay male couple and some residents and drug dealers from favelas in the Complexo da Maré region, this article examines the relationship between violence and subjectivity, having as a horizon of reflection the debate over different ways of producing bodies and genders. By incorporating W. Benjamin's (2013) invitation to conduct a "critique of violence", this social phenomenon will be considered from its positive aspect - as a performance act that produces bodies, moralities and genders in that context. Bodies, moralities, genders as well as violence itself are comprehended based on their (re)elaboration through the narrative context.
\end{abstract}

Keywords: Bodies, Genders, Violence, Subjectivities, Narratives. 
Quando chegamos a uma consideração final da relação entre violência e gênero, é claro que a violência de todos os tipos está marcada por gênero em sua representação, na maneira como é pensada e constituída como fato social. Em sua realização como prática social é parte de um discurso, ainda que contraditório $e$ fragmentado, sobre a diferença de gênero (Henrietta Moore em Fantasias de poder e fantasias de identidade: gênero, raça e violência).

Uma das formas amplamente difundidas de compreender os processos que envolvem a constituição de sujeitos políticos específicos é observando a centralidade que as situações de violência assumem na articulação dessas coletividades, como também de discursos específicos cuja finalidade é a garantia de direitos. Os atos violentos e suas respostas, seja através de políticas, novas violências, narrativas, performances corporais etc, são também tomados pelos sujeitos como meios de constituir corpos e moralidades contextuais, estabelecidos por e em relação àquelas cenas. Noções como corpo, gênero e indivíduo são então, em diversas análises, desubstancializadas e compreendidas como resultados de relações e cenas fortemente marcadas por dinâmicas temporais, espaciais e performativas (Gregori, 1993; Stoler, 1997; Das, 2008; Halberstam, 2005; Blázquez, 2010).

Dando continuidade a essas perspectivas, e atento ao desafio de realizar, tal como proposto por Walter Benjamin (2013), uma "crítica da violência", isto é, deslocando a compreensão desse fenômeno do debate em torno da finalidade da violência ou ainda da qualidade, justiça ou valor dos meios através dos quais ela é produzida, para observá-la em si mesma, como instauradora de sociabilidades e moralidades, como ato(r) performático que produz sujeitos e relações, trato de uma situação de violência (e de sua narrativa) a que tive acesso durante a minha pesquisa de mestrado. O postulado de Benjamin é caro à compreensão do caso que trago aqui, pois, em um primeiro momento, permite observar a violência descrita em seu caráter positivo, produzindo 
corpos e moralidades naquela relação/situação; e, em um segundo momento, observar esses corpos $e$ moralidades sendo (re)construídos através do contexto narrativo.

As violências, portanto, não se encerram nos eventos em si, mas têm a sua duração garantida não apenas nas lembranças que os sujeitos podem carregar consigo ao longo de suas vidas, ou ainda nos processos judiciais que deram origem, mas também na existência de "atos de se contar o que se passou" em diversas situações. Nesse sentido, partindo da compreensão do "ato de testemunhar como uma maneira de entender a relação entre violência e subjetividade" (Das, 2011:39), abordo um evento narrado e vivido por um dos meus interlocutores na pesquisa que desenvolvi no mestrado (Lopes, 2011). Além de observar algumas dinâmicas ocorridas no evento, tratarei da performatividade desse ato de contar e de suas consequências em termos de constituição de corpos, gêneros, violência e subjetividade.

A pesquisa que deu origem a este artigo teve como objetivo apreender os discursos de jovens não heterossexuais moradores de favelas da Maré ${ }^{1}$ no Rio de Janeiro, a respeito das (homo)sexualidades e de relações de gênero. Ao longo do trabalho de campo, pude estabelecer intensa relação com duas redes de jovens moradores da Nova Holanda, uma das favelas que compõem o Complexo de Favelas da Maré, mas também com seus amigos de outras regióes da cidade, familiares e outros personagens com quem mantiveram contato. Aliás, a explicitação da realização do trabalho de campo "a partir da Maré", não "na Maré", objetiva ressaltar a centralidade que as circulações tiveram

1 Localizada na Zona Leopoldina da cidade, às margens da Baía de Guanabara e cortada ao meio por três vias expressas (Avenida Brasil e Linhas Amarela e Vermelha), o Complexo de Favelas da Maré, ou apenas Maré, é composto por 16 favelas com diferentes modalidades de habitações (barracos de madeira, palafitas, casas de alvenaria, conjunto habitacionais favelizados, morro, entre outros). Conforme os dados da Prefeitura do Rio, é o sétimo maior bairro - $e$ primeira favela - em número de moradores, com uma população estimada segundo o Censo 2010 - em 129.770 pessoas, distribuídas em mais de 40 mil residências. 
na minha etnografia, dado que uma substantiva parte dela foi realizada acompanhando esses jovens por espaços de sociabilidade externos à Maré, observando seus trânsitos e os processos de construção de si em e através de diferentes espaços.

A opção por esse caminho se deu pela crença de que apenas pela observação sistemática de seus cotidianos poderia apreender não apenas as suas representações em torno de gênero, sexualidade e favela, mas observar as dinâmicas que os constituíam em ato e de modo articulado. Nesse sentido, as observações $e$ as conversas permeavam uma variedade de experiências que iam desde situações de violência, passando por conflitos familiares e relações afetivo-sexuais, a questionamentos a respeito da vida profissional e escolar. A dissertação, portanto, se dedicou a investigar os modos de "construção de si" desses jovens, considerando percursos e negociações que envolviam esfera familiar, participação em projetos e movimentos sociais, convivência com o tráfico, violência interpessoal, desejos e afetos, na elaboração de moralidades específicas.

Neste artigo, a partir de uma das narrativas de violência que pude ouvir durante a pesquisa, reflito sobre as relações entre corpos, gêneros, subjetividades e violências, evidenciando que esse ato, em articulação com esses quatro aspectos de observação, produz e instaura moralidades específicas. Inicio, portanto, com a descrição da cena e situação em que a narrativa veio à tona pela primeira vez, passando à situação de violência $e$, em seguida, indicando os fundamentos em que se assenta a minha análise em termos dos estudos de gênero, corpo e subjetividade. $\mathrm{O}$ entrecruzamento entre a situação de violência e as reflexões que deram suporte à minha compreensão é trazido em seguida, mediado pela explicitação da possibilidade de reinvenção dos sujeitos, de seus corpos e gêneros através do contexto criado pela narrativa. Por fim, reflito sobre as razões, usos e apropriações dessa narrativa de violência entre os jovens com quem realizei esta investigação, considerando os aportes aqui utilizados e o seu potencial para a pesquisa que empreendi. 


\section{Contexto da narrativa}

Em abril de 2009, quando visitava a Nova Holanda pela segunda vez, tive acesso ao relato de um evento que depois ouviria tantas vezes. Sentados em uma mesa de bar, na calçada da rua "principal", comemorávamos o aniversário de uma amiga minha que iniciava o namoro com uma moradora daquela favela. Aquela era a primeira visita noturna que fazia à Nova Holanda $e$ tinha grande expectativa em conhecer "os amigos da Fabiana" - a quem tanto se referia Fernanda, a minha amiga. Logo no entrecruzamento da Rua Principal com a Rua Teixeira Ribeiro, um ponto de grande movimentação da favela, fui recepcionado por Fernanda e Fabiana. Assim que cheguei ao bar avistei os rapazes (Augusto, Pedro, Rodolfo e Cláudio) que estavam sentados em uma mesa. ${ }^{2}$

O cenário era barulhento, movimentado e descontraído. Intercalavam-se conversas sobre namoro, sexo, carnaval e outros eventos. Entre cervejas e gargalhadas, uma narrativa despertou especial atenção da minha parte: a violência sofrida por Cláudio e seu namorado na época - no Parque União, favela vizinha $e$ também pertencente ao Complexo da Maré, na madrugada do dia 25 de dezembro de 2008. Fernanda havia me antecipado esse evento, mas dizendo apenas que um dos amigos da sua namorada tinha passado por uma "situação tensa", sem revelar detalhes. Fiquei muito interessado, mas imaginei que pudesse ter acesso ao relato apenas em situação mais reservada, tranquila; pensei que talvez fosse ouvi-la em uma entrevista. Contudo, foi naquele clima de descontração e intercalado por muitos risos que esse evento foi trazido à tona - e era assim que, depois poderia observar, ele era retomado em distintas situações.

Entre as conversas que mantínhamos, Fernanda lembrou meu interesse de pesquisa na Maré. Nesse momento, em um tom

\footnotetext{
2 Durante a noite algumas pessoas passariam pela mesa e Monique, uma amiga dos meus interlocutores, se incorporaria a ela no fim do dia. Com o objetivo de preservar o anonimato dos meus interlocutores, todos os nomes são fictícios.
} 
jocoso, que parecia visar constranger e provocar Cláudio, mas que ao mesmo tempo indicava um entendimento que reconhecia aspectos que seriam caros a alguém interessado em pesquisar "LGBTs na Maré", Augusto o incitou a contar a "surra que ele levou dos mavambos ${ }^{3}$ no Parque União". Todos riram, eu demonstrei um tímido interesse em saber do evento, ainda orientado pela expectativa de uma situação mais reservada para conhecê-la, e Cláudio que, inicialmente, também sorriu expressando timidez, iniciou a narrativa.

\section{O evento}

Na noite de Natal, entre os dias 24 e 25 de dezembro, esse grupo de amigos passou boa parte do tempo na festa realizada pela família de Fabiana - na porta da casa dela. Haviam bebido bastante, alguns dos rapazes se vestiram com roupas e calçados femininos, dançaram, brincaram - contaram que se divertiram bastante. Além desse grupo de amigos, dos familiares da Fabiana e de outros moradores da favela próximos a essa rede e à família, também estava presente Guilherme, morador de Nova Iguaçu ${ }^{4}$, namorado de Cláudio.

Segundo narrado, já era mais de cinco horas da manhã quando Cláudio, Guilherme e Rodolfo saíram das comemorações na casa de Fabiana em direção à casa do último, no Parque União. Chegando lá, Rodolfo subiu para casa, enquanto Cláudio e Guilherme permaneceram em um misto de quintal e beco próximo à casa. Eles transaram e depois permaneceram no mesmo local conversando. Depois de ter passado um curto

\footnotetext{
3 "Mavambos" é um dos termos nativos utilizados para se referir aos traficantes de drogas. Apesar de Augusto ter recorrido ao termo nesse momento, não observei o uso frequente dessa categoria em outras interações com essa rede de sociabilidade. Contudo, ela é presente entre outros grupos e indivíduos com os quais interagi ao longo da pesquisa.

4 Nova Iguaçu é um dos municípios que compõem a Baixa Fluminense, Região Metropolitana do Rio de Janeiro. Com pouco mais de 812 mil habitantes (IBGE, 2012), é o quarto município mais populoso do estado.
} 
período do tempo, Cláudio conta que foi interpelado por um vizinho de Rodolfo, doravante, vizinho, que perguntou se ele estava "trepando" ali. Cláudio respondeu que não e, então, o vizinho mandou ele "se adiantar". ${ }^{5}$ Cláudio disse que combinou de dormir na casa de seu amigo, mas o vizinho, saindo do local, insistiu para que ele "se adiantasse". Cláudio conta que, um tempo depois, Guilherme viu que o vizinho os observava pela janela de seu apartamento. Segundo narrou, logo depois ele já teria descido com um pedaço de pau para agredi-lo. Cláudio entrou na frente e recebeu o golpe (1). ${ }^{6}$ A confusão aumenta. $\mathrm{O}$ conflito que inicialmente envolvia apenas os três, já contava com alguns amigos do vizinho que se incorporaram. A tensão já estava presente e o desenrolo $o^{7}$ foi apresentado como um caminho inevitável (2). Cláudio conta que tentou chamar Rodolfo - que era "quem morava lá" - para acompanhá-los no desenrolo, mas foi impedido pelo vizinho e os amigos dele.

Cláudio revela que assim que todos chegaram na "boca" a questão foi apresentada pelo vizinho como "pederastia na rua". Segundo ele, após o vizinho apresentar a sua versão, um dos traficantes teria perguntado se ele era gay e se estava transando. Cláudio teria respondido negativamente todas essas questões, dizendo que ia dormir na casa de um amigo que morava lá. Ante as suas refutações, iniciaram um novo inquérito com Guilherme. Ao contrário de Cláudio, Guilherme respondeu que ele era gay e

5 "Se adiantar" significa andar rápido, sair de onde está. Nesse caso, o vizinho o mandava ir embora, sair dali.

${ }^{6}$ A seguir, como forma de apresentar melhor o texto e suas reflexões, essa numeração será retomada.

7 "Desenrolo" ou "desenrolar" são categorias êmicas empregadas para se referir ao desenvolvimento de um diálogo em que os sujeitos envolvidos tratam de determinado assunto para, de algum modo, apresentar uma solução. Apesar da categoria "desenrolo" não ser utilizada apenas na interação com traficantes ou em dinâmicas que envolvem alguma violência ou tensões dessa natureza, muito comum, por exemplo, é dizer que "fulano" desenrolou com "beltrano" e eles ficaram à noite, ou que alguém conseguiu um desconto em algum produto/serviço após desenrolar com o vendedor/prestador do mesmo, é esse o sentido empregado ao longo desta narrativa. 
que eles tinham transado. Quando perguntado disse que morava em Nova Iguaçu. Cláudio conta que eles foram separados, tendo ficado cada um em um lado da rua, nas calçadas. Nesse momento, um dos traficantes que havia ficado ao lado do Cláudio ameaçou dizendo que com ele (Cláudio) não poderia fazer nada, pois era $\mathrm{cria}^{8}$, mas que com "ele..." (Guilherme) (3).

Nesse momento, Otávio, um traficante influente na Nova Holanda, passou próximo de onde estavam. Cláudio pediu para que ele fosse chamado - dizendo que eles moravam na mesma rua. No mesmo momento, um rapaz, vinculado ao tráfico do Parque União, Rogério, também passava pelo local. Cláudio teria solicitado que esse também fosse chamado, já que tinham estudado juntos (4). Rogério, ao contrário de Otávio, parece ter tido um papel importante. Cláudio conta que pensou que estava correndo risco de morte. Considera que a defesa de Rogério junto aos outros traficantes foi a principal razão para a manutenção de sua vida e, de certo modo, o fato de não ter apanhado como seu namorado. Segundo disse, Rogério intercedeu dizendo que Cláudio era seu conhecido, que era cria da favela e que já o tinha salvado de muitas situações; assim como Cláudio, Rogério informou que tinham estudado juntos. Antes disso, Rogério teria orientado Cláudio que dissesse que não era gay e que não eram namorados. Contudo, Guilherme já havia dito o contrário.

Durante essa discussão outra pessoa desempenhou um forte papel no conflito: Rafael, também traficante na Nova Holanda. Ele, que teria atuado contra Cláudio e seu namorado no

8 Com cria, outra categoria nativa importante nessa narrativa e no cotidiano de moradores de favelas no Rio de Janeiro, refere-se a quem é próprio, oriundo, nascido em determinada localidade - portanto, é possível dizer que Cláudio é cria da Nova Holanda. O seu uso, como debatido nos artigos incluídos na coletânea organizada por Machado da Silva et alii (2008), trata-se também de uma reelaboração que moradores produzem dos traficantes na tentativa de humanizá-los. Essa noção também é central quando contraposta ao traficante que não é cria, considerado mais violento e menos compreensivo nas interações cotidianas com e entre "os moradores", dada a ausência desse traço original com o local onde atua,. 
desenrolo, parecia querer "ferrá-los". ${ }^{9}$ Caminhando para o desfecho do evento, Cláudio conta que ele foi protegido, em razão da intervenção de Rogério, e que Guilherme tomou uma surra: vários traficantes, o vizinho e seus amigos "juntaram"10 no Guilherme. Ao Cláudio, teria sido reservada a especial atenção de um dos traficantes, Rafael, que "não queria deixar passar". Segundo Cláudio, Rafael teria afirmado que queria, ao menos, dar "um soco no peito" (5). Cláudio conta que quando o soco foi desferido, ele o recebeu com peito estufado e o encarando, olhando nos olhos, sério. Segundo ele, o soco o atingiu com grande força, mas se manteve com aquela postura, pois "ele queria" que Cláudio mostrasse fragilidade (6). Ante a sua reação, Cláudio conta que esse "cara da boca" comentou com seus pares que ele era "abusado" pela reação que teve (7). Após todos esses momentos, os rapazes foram liberados, mas tiveram que passar antes por um "corredor polonês" (8). ${ }^{11}$

Cláudio conta que ambos foram até a parada de ônibus em Ramos, bairro vizinho ao Complexo da Maré, onde Guilherme pegaria um ônibus à sua casa. Enquanto aguardavam o transporte, Cláudio chorava e, em razão disso, Guilherme perguntou se as feridas deixadas estavam doendo. Cláudio respondeu que não, que chorava porque era um "absurdo" o que havia acontecido com eles (9). Segundo ele, tudo teria ocorrido

9 Cláudio contou que Rafael já era conhecido como alguém que "não gosta" dos gays. Aquela não teria sido a primeira vez que ele teria manifestado certa contrariedade com os dois. Ao longo da pesquisa, através de diferentes interlocutores, ouvi diversos relatos da agressão e ameaças desse traficante contra gays e travestis.

10 Juntar ou juntaram refere-se a uma situação em que dois ou mais indivíduos atuam de maneira violenta contra uma ou mais pessoas. Em seu cerne, a ideia conserva o reconhecimento de determinada desigualdade, dado que "o grupo que junta" está numericamente em vantagem sobre aquele que "é juntado".

11 "Corredor polonês" é uma disposição de espaço onde um grupo é dividido em duas fileiras, uma de cada lado, formando um espaço entre elas. Essa organização configurará um corredor, cujo sentido é materializado na passagem por um sujeito (ou mais) nesse corredor, recebendo golpes (chutes, socos, xingamentos etc.) enquanto o atravessa. 
não pelo fato deles terem transado, mas por serem gays. Afirmou que se fossem heterossexuais e se estivessem trepando "no meio de todo mundo", as consequências não seriam as mesmas. Ainda é interessante destacar que Fabiana, nesse momento do relato, corta Cláudio e argumenta que no caso de duas mulheres poderia ter ocorrido não uma surra, mas estupro.

\section{Diálogos sobre gênero e corporalidades}

O relato trazido por Cláudio nos coloca interessantes questóes a respeito das suas leituras sobre o ocorrido. Seu corpo, tal como apresentado, é central na interação narrada, visto que ele parece ter sido palco de uma disputa que orientava não apenas os golpes proferidos, mas a sua reação diante deles - a violência, portanto, não era constituída apenas pelos gestos em si, mas também por uma espécie de antecipação das reações $e$ expectativas diante deles, $e$, ao mesmo tempo, pela performance produzida ao golpear $e$ ao ser golpeado. Esse embate é fundamentalmente marcado por disputas em torno de performances de gênero, que, entendido de um modo expandido e elástico, não será definido por uma correspondência/coerência com um "corpo biológico" tomado de um modo pré-discursivo (Butler, 2008), isto é, como um item estabelecido por uma "natureza" existente anterior e independente de relações sociais, mas em diálogo com outros significantes presentes nas situações relatadas. O gênero, portanto, é mobilizado, ou construído, a partir das cenas, dos lances, dos movimentos trocados, mantidos, co-produzidos, por esses contextos em negociação.

A revisão crítica dos principais postulados de algumas perspectivas do pensamento feminista, elaborada por Collier $e$ Yagisako (1987), levanta algumas questões importantes para esse caso. Para realizarem seu objetivo, as autoras retomam diferentes leituras que foram hegemônicas ou mesmo que disputavam algum protagonismo no interior do campo, mas que, para elas, pecam por recorrerem à mesma naturalização de uma dicotomia fundamental - homem $e$ mulher $-e$ por se fundamentarem a 
partir de definições, demandas e conceituações caras à sociedade ocidental. "Natureza/cultura", "doméstico/público", "reprodução/ produção" e outras perspectivas que ressaltam o "ponto de vista das mulheres" ou o "sistema de prestígio masculino" são questionadas não só por suas tentativas de universalização, como também por se constituírem de maneira simples e homogênea quando temos em conta, inclusive, o próprio Ocidente. Além disso, como todas as oposições estruturais universais, elas não apenas eliminam o que se coloca fora delas, como impossibilitam a compreensão das mudanças e transformações operadas através das ações dos sujeitos em seu interior. Se não se reconhece a ação social sobre elas, essas oposições são retiradas do próprio plano das relações sociais.

$\mathrm{O}$ uso daqueles binarismos $e$ sua constituição/ reconhecimento no interior de determinadas relações de desigualdade são outros pontos de crítica dessas autoras. Segundo indicam, a leitura do "doméstico" ou do "reprodutivo" como inferior é conformada pela perspectiva feminista ocidental. O caráter relativista fundante e estruturante da antropologia é abandonado por essas leituras, dado que universaliza o sistema de hierarquias e prestígio tal como concebido entre nós. Se é mais simples compreender esse questionamento quando falamos em público/privado ou, a partir do enfoque do feminismo marxista, em produção/reprodução, é interessante notar que a própria diferenciação entre homem e mulher, concebida como uma diferença natural, pré-cultural, e a compreensão de que todas as sociedades se fundam sobre um sistema de desigualdades, são tomadas como indicativos dessa perspectiva centrada no Ocidente.

$\mathrm{Na}$ mesma direção dos questionamentos apresentados por Collier e Yanagisako (1987), Strathern (2006) radicaliza tais críticas e propõe que um dos desafios é compreender que as divisões de esferas que cotidianamente utilizamos, acadêmicos e feministas, são imagens que não existem em si, mas que são fruto de determinada forma de ordenamento/estruturação das maneiras de pensar e de construir problemas. Essas imagens, como analisa, 
constituem (e são constituídas) pela projeção de valores que implicam na definição, ou enquadramento, entre coisas, aspectos, temas e comportamentos relativos aos homens $e$ outros às mulheres, modelando "uma fronteira ideacional entre os sexos [que] torna-se o meio através do qual a própria possibilidade de ação é apresentada" (Strathern, 2006:129).

A partir disso, é possível compreender um dos pilares das reflexões realizadas por Strathern (2006): a crítica à busca de delimitação e de diferenciação entre áreas temáticas. Esse questionamento que, como vimos acima, assenta-se na observação de que disposições/valores são produzidos/emergem da própria divisão que, em princípio, poderia ser considerada por muitos como não generificada, como conceitual, teórica ou metodológica, tem em seu cerne uma associação entre esferas dos homens e outras das mulheres, delimitando, como trazido no trecho citado acima, "a própria possibilidade de ação". Assim, esse modo de reflexão baseado na definição de áreas temáticas, para essa autora, constitui um movimento analítico fortemente marcado por valores ocidentais, sendo necessário, portanto, um deslizamento de tais perspectivas para, em um segundo momento, ao retornar a elas, melhor compreendê-las. Nessa direção, Strathern (2006) acredita que olhar para o caso melanésio, sem perder de vista diversas indagações feministas, é um caminho eficaz para perceber o caráter histórico e local de um modelo, de um modo de operar com o pensamento, que se pretende universal.

Nesse sentido, as críticas de Strathern a definições de esferas delimitadas de gênero e mesmo de setores da vida social são estruturadas pela valorização de uma perspectiva situacional, centrada nos eventos e cenas, nos contextos. A autora (2006) nos propõe, portanto, que se abra mão dos "modelos" como "modelos", isto é, de um conjunto de ações, significados e valores pensados como ordenadores ou matrizes em diferentes situações etnográficas, pois "apreende-se melhor a elaboração de domínios como uma atividade, [compreendendo] a criação/implementação da diferença como um ato social" (Strathern, 2006:156). 
A partir da flexibilização das oposições tomadas de modo estrutural, universal e não questionadas, da percepção que domínios e diferenças são forjadas em atos sociais e, portanto, da valorização da relacionalidade, Strathern postulará não a existência de dois gêneros, dicotômicos, em oposição e exclusão mútuas, mas de signos que circulam, que se relacionam em determinados contextos e que, desse modo, constituem pessoas generificadas e socialidades específicas. Assim, ela argumenta que

\begin{abstract}
as pessoas impactam [impinge] umas às outras de maneira diferenciada [ressaltando que] (...) por um lado, a eficácia deriva da ação coletiva, baseada no compartilhamento de identidade; por outro, de relações particulares, baseadas na interdependência e na diferença entre as pessoas (Strathern, 2006:152).
\end{abstract}

As ideias de impacto, eficácia e interdependência são fundamentais pois deslocam a reflexão de postulados que já haviam sido questionados acima, ressaltando os sentidos produzidos pelos/nos atos sociais. Ao considerá-las, Strathern (2006) não recorre a compreensões como papel de homem/mulher, ação individual (e, por extensão, as de indivíduo e/ou sujeito), ou ainda ideias substancializadoras/ essencializadoras dos sujeitos e seus gêneros atribuídos, visto que não só não são fiéis às formas de pensamento melanésia, como também provocam bias à reflexão antropológica. Desses questionamentos de Strathern (2006), devemos estar especialmente atentos à sua compreensão do gênero como algo imbuído/marcado por uma determinada eficácia, produzida pela ação recíproca e interdependente de impactar um ao outro. Nessa direção, é oportuno incorporar as reflexões de Judith Butler (2003) e sua compreensão do gênero a partir de sua dimensão performática para esse debate.

Butler, em Problemas de gênero (2003), também investe parte das suas reflexões no questionamento de uma essencialização/naturalização do gênero. Considerando que algumas abordagens desse conceito o tomam de um modo pré- 
discursivo, a autora propõe reinvesti-lo, em um primeiro momento, de seu caráter sociohistórico, e, em um segundo momento, pensar as possibilidades hermenêuticas ao considerá-lo em sua dimensão relacional, interativa. Desse modo, recupera o "dispositivo da sexualidade" foucaultiano (Foucault, 1984) para (re)pensar as categorias relativas ao gênero, ao sexo e ao desejo, a partir da lógica específica desse dispositivo.

Ao tratar dessas questões, a autora parece retomar aspectos da reflexão de Rubin (1975) a respeito do "sistema sexo/gênero", visto que centra a sua desconstrução nas instituições do "falocentrismo" e da "heterossexualidade compulsória". Assim como Rubin, Butler (2003) acredita que há uma íntima relação entre sistema binário de gênero e heterossexualidade compulsória, resultando na emergência e no fortalecimento de um - ao mesmo tempo que esse é mecanismo de constituição e fortalecimento de outro. Segundo as autoras indicam, o problema a ser enfrentado é a coerência materializada e forjada entre os dois sistemas que, relacionados ao desejo ou mesmo ao parentesco, conduzem a sua mútua alimentação/manutenção.

Portanto, o que se pretende dizer/identificar/produzir ao recorrer a uma dessas "identidades dadas" como, por exemplo, "mulher"? O que fica "de fora"? Que apagamentos são conduzidos nesse processo? Alguém é silenciado? Quem? Para refletir sobre essas perguntas, Butler (2003) parte do próprio questionamento do sujeito do feminismo, visto que se constitui a partir da reivindicação de um elemento atemporal, de uma ficção que, em si mesma, fundamenta aquele discurso. Segundo afirma, a demanda por encontrar uma "base universal para o feminismo" que fundamentaria a crença na existência de uma "identidade comum" em diferentes sociedades - as mulheres -, pode incorrer, na verdade, em dar passos atrás para uma política feminista. Ela defende, portanto, que é preciso refutar "as próprias reificações do gênero e da identidade", indicando que a compreensão de uma relação direta entre gênero e sexo colocaria em risco o próprio potencial analítico que a diferenciação entre essas categorias trouxe. 
Além do reconhecimento da possibilidade de se "jogar com esses pares", é fundamental o questionamento do binarismo de gênero e de uma suposta unidade no interior de cada um desses pares. Portanto, torna-se impossivel tomar gênero como algo absoluto, anterior aos contextos e aos corpos. Do mesmo modo, Butler (2003) defende que não há corpo sem gênero, logo, a compreensão de que o gênero se inscreve/pode se inscrever em um corpo, como etapas, momento distintos, também está equivocada, pois ela acredita que não há um corpo anterior, prévio à sua constituição também como gênero. Ou seja, não existem gêneros ou corpos prévios às situações, mas elaborações que dependem de configurações marcadas por um conjunto de relações dadas e construídas nos contextos específicos que, então, fazem corpo e gênero. Nesse aspecto, é interessante tomarmos essas reflexões como uma possível resposta à provocação feita por Strathern (2006:107):

Podemos perguntar-nos, a partir disso, que sociedades adotam de fato um conceito de pessoa sem gênero, neutra, sobre a qual a diferença de gênero se inscreve, e que sociedades apresentam a ideia de que não há pessoas como sujeitos que não sexuados.

Considerando que não tomamos mais "o homem" ou "a mulher" como portadores de uma substância pré-discursiva, anterior, que os constitua previamente, tampouco que "o gênero masculino" ou o "gênero feminino" seja inscrito nesses corpos, como, então, se dá essa constituição dos sujeitos como corpos generificados? Em suas reflexões, Butler ressaltará que gênero não é algo "substantivo", mas também não significa que é possível compreendê-lo como "atributos flutuantes". A sua materialidade, ou, como ela diz, o "seu efeito substantivo", é performativamente produzido e imposto

pelas práticas reguladoras da coerência do gênero. (...) Não há identidade de gênero por trás das expressões do gênero; essa identidade é performativamente construída, pelas 
próprias "expressões" tidas como seus resultados (Butler, 2003:48).

Contudo, ao mesmo tempo que ressalta uma ampla abertura de possibilidades constitutivas do corpo, dado que centra-se na performance e na cena, Butler (2003) recorda que existem algumas limitações para essas possibilidades inventivas: chama atenção para os próprios limites discursivos que conformam/possibilitam/tornam imagináveis tais experiências em determinados contextos socioculturais. ${ }^{12}$ Como destaca, "a coerção é introduzida naquilo que a linguagem constitui como o domínio imaginável do gênero" (Butler, 2003:28).

Antes de retornar ao evento objeto deste artigo, considero oportuno destacar o potencial analítico trazido pela compreensão de "embodiment' em Csordas (1999), visto que ao refletir sobre os modos pelos quais a antropologia tem se apropriado do corpo, lança luz para outras das suas dimensões constitutivas. Uma importante contribuição do autor, significativa à análise empreendida aqui, refere-se aos questionamentos a respeito dos limites da própria corporalidade, do corpo e de suas fronteiras, nos levando a indagações que avançam na crítica ao "essencialismo biológico" e ao "dualismo de gênero". O corpo que, tradicionalmente, é compreendido em razão/referência ao indivíduo, isto é, um indivíduo, um corpo, dois indivíduos, dois corpos, cinquenta indivíduos, cinquenta corpos, deve ser

\footnotetext{
12 Sobre esse aspecto, é interessante pensar os diferentes cenários imaginativos/possíveis em termos de gênero $e$ da construção de outras materialidades do corpo nas análises trazidas por McClintock (2003) a respeito de gênero, raça e imperialismo, em Díaz-Benítez (2010) ao tratar da produção de uma pornografia mainstream, também nas discussões a respeito dos limites e do que é o corpo/gênero considerados "pela ciência", em Haraway (1989) e FaustoSterling (2000), ou na construção de uma corporalidade queer presente nas reflexões de Halberstam (2005). Em diferentes espaços, com diversas demandas $e$ através de distintas atuações, os limites do que é gênero, raça e corpo, bem como do que é possível, desejado e abjeto, são reconduzidos a partir de mapas de entendimento (de imaginação) construídos a partir das distintas configurações discursivas (in) disponíveis.
} 
observado em relação, construindo corporalidade(s) que, em verdade, pode $(\mathrm{m})$ fundir ou multiplicar o(s) corpo(s) e o(s) indivíduo(s), de acordo com as relações de interdependência que são construídas entre os que se encontram em interação. É sobre essa qualidade e possibilidade do(s) corpos(s) que Csordas (1999) chama atenção.

Esse autor argumentará, portanto, que o corpo é uma condição existencial da vida, mas que é preciso estar atento ao fato de que existem múltiplos modos, diversas formas, de "embodiment". Compreender esses modos constitui, para ele, um meio de entender a própria cultura. Nesse sentido, como destaca, o paradigma do "embodiment" não constitui, em verdade, uma proposta de olharmos para uma questão nova, mas de (re)conhecermos o corpo como um dispositivo metodológico em nossas análises. Propõe que a nossa compreensão do corpo como origem/depositório de significados e/ou efeito discursivo seja deslocada tendo em vista o reconhecimento do corpo como experiência e subjetividade.

A discussão desses aspectos foi importante para localizar os pressupostos teórico-metodológicos dessa reflexão. Essas considerações a respeito do corpo e do gênero, de maneira desubstancializada, valorizando dinâmicas contextuais $e$ interativas, reconhecendo o caráter performático e subjetivo dos mesmos, permite compreender a violência sofrida por Cláudio $e$ Guilherme como uma disputa em termos da construção de gênero(s) e corpo(s)/corporalidade(s). Nesse sentido, considero oportuno radicalizarmos as discussões sobre a ausência de um corpo de maneira pré-discursiva, bem como das dificuldades de estabelecermos as fronteiras entre os corpos e dos benefícios da compreensão do embodiment, como tematizado por Csordas, $e$ refletirmos sobre a violência narrada como um conflito cuja marca é a constituição/disputa de uma corporalidade (1999). 


\section{Sobre a situação de violência $e$ a narrativa: seus efeitos $e$ usos}

Entender a violência em seu aspecto positivo é eficaz como forma de pensar não apenas o evento e a narrativa produzida acerca dele, mas alguns dos processos que envolvem a própria constituição de corpos generificados. O que se pode notar, ao longo do relato, é um embate em torno da definição de uma situação que, a partir da classificação de Csordas (1999), podemos considerar que se deu através da definição de um embodiment, cujo cerne está nas demarcações de corpos/gêneros possíveis.

Em sua narrativa, Cláudio destaca alguns aspectos que desejo relembrar aqui: 1) Ele entra na frente do rapaz e recebe o golpe do vizinho; 2) o "desenrolo" torna-se um caminho inevitável; 3) há o questionamento a respeito da orientação sexual e de uma possível relação sexual; 4) Cláudio identifica pessoas de sua rede pessoal e os convoca para o desenrolo; 5) um traficante não abre mão de proferir um soco no peito de Cláudio; 6) ele reage estufando o peito e encarando seu algoz; 7) por sua reação, Cláudio é considerado abusado pelo agressor; 8) o desenrolo tem um desfecho; e 9) o choro no ponto de ônibus.

A indicação desses momentos revela um aspecto estruturante da situação de violência em si, mas também dela como objeto de narrativa: uma intensa disputa a respeito de como constituir moralmente, principalmente, Cláudio, mas também os outros atores envolvidos naquele embate. Nesse sentido, é oportuno indagar o que querem dizer, o que significam $e$ o que produzem os nove tempos específicos que indiquei no parágrafo anterior, como também a narrativa e o ato de contar a terceiros.

Como uma ampla literatura a respeito da construção social de gênero e sexualidade indica, a revelação de experiências homossexuais tende a feminizar os sujeitos que são identificados com/por tais práticas ou desejos. Assim, é possível considerar que, no primeiro instante, esses corpos, tomados como contaminados pelo feminino em razão da classificação em torno de tais experiências afetivo-sexuais, foram alvo de uma primeira tentativa de (re)afirmá-los como tais através da agressão cometida pelo 
vizinho. Contudo, ao se colocar na frente de seu namorado $e$ receber o golpe, Cláudio rejeita essa nomeação ao performar um gesto que remete à força, coragem, atividade e resistência, que não apenas não chancela a marca inicialmente sugerida pelo vizinho, como o reposiciona naquela interação conflituosa. Se, em princípio, houve uma tentativa de subalternizá-lo pela violência e, em articulação com ela, por atributos/expectativas de gênero que o vizinho possuía a respeito deles, no decorrer da cena, em razão da eficácia da atuação de Cláudio, constituem-se dois corpos que acionam signos que, naquele contexto, são associados ao masculino: força, coragem, violência etc.

Ao serem levados para o desenrolo por um grupo de pessoas, contra as suas vontades, constituía-se uma situação de relativa subalternidade do casal. Cláudio reconheceu o novo contexto e procurou reequilibrar a relação de forças tentando convocar seu amigo, morador daquela favela. Ao considerar que foi a acusação de pederastia que fundou o desenrolo, pois foi assim apresentada pelo vizinho-denunciante, é possível compreender que os corpos desses jovens, nessa nova sequência da interação, foram, mais uma vez, construídos em torno de aspectos feminizantes: a passividade ao serem conduzidos ao desenrolo sem a sua aceitação (ou baixa capacidade de reação/resistência a isso), a fragilidade que se produzia por não estarem na favela em que residiam ou com algum morador que pudesse acompanhá-los naquele desenrolo, e a própria homossexualidade como razão inicial daquela situação. A necessidade de se justificar pelo tipo de avaliação moral de que eram alvo, o insucesso e a não eficácia dos seus argumentos, mais a ausência de algum mediador local que pudesse agregar valor à sua defesa, pareciam constituí-los, mais uma vez, através de um polo inferior, menor, de algum modo, com baixa dignidade. Além disso, podemos indicar a própria confirmação, da parte de Guilherme, de que eles eram namorados e que mantiveram um relação sexual como outro elemento que confirmava a classificação deles em um polo "mais feminino". 
Contudo, é interessante observar o momento em que houve um realinhamento da constituição de gênero desses sujeitos, um processo de dignificar-se no interior daquelas relações. Nesse sentido, é interessante refletirmos sobre a própria característica do desenrolo como um espaço/tipo específico de socialidade. Como uma instância mediadora e definidora de relações, ele é, podemos considerar, eminentemente marcado por referências a valores relacionados ao que, em nossa sociedade, associar-se-ia ao masculino. Embora esteja disponível a todos e, de fato, muitas mulheres recorram ao desenrolo ${ }^{13}$, trata-se de uma prática geralmente acionada por homens, considerando que, em geral, as decisões são definidas e tomadas por outros homens. É também uma instância, em certo sentido, política e pública. Há, na verdade, a indicação de que os homens sejam os atores reconhecidos (ou mais apropriados) a recorrem a ele, ou ainda que as mulheres estejam acompanhadas ou sejam respaldadas para realizarem tais empreendimentos. $\mathrm{Na}$ verdade, ao se constituir em uma instância em que um conflito será dirimido considerando não apenas o incidente em questão, mas a íntima relação entre prestígio, honra, influência e poder na constituição dos sujeitos morais envolvidos, podemos reconhecer e observar que o desenrolo é uma experiência que aciona uma série de referências constituídas e constituidoras de uma zona moral que, naquele contexto, é considerada como cara aos homens. ${ }^{14}$ Desse modo, ao recorrem a ele, os sujeitos, de algum modo, deslocamse na direção do polo masculino, nessa nossa linha imaginária $e$ (des)contínua de atribuições de gênero. É claro, no entanto, que a constituição moral de sujeitos é cruzada por uma série de outros valores, marcadores e referências, reconhecendo, por exemplo, nas mulheres líderes políticas ou religiosas, mães e/ou esposas, um valor especial na cadeia de relações em termos de

\footnotetext{
${ }^{13}$ Para uma interessante análise de uma dessas situações, ver Mattos (2014).

${ }^{14}$ Aqui são claros a referência e o diálogo com os contextos etnográficos explorados por Lila Abu-Lughod (1988) e Strathern (2006), cuja associação entre prestígio e masculino é fortemente marcada nas relações que relatam.
} 
possibilidades/poderes para apresentarem demandas em desenrolos. ${ }^{15}$ Mas, retomando a discussão realizada a partir de Strathern (2006) e Butler (2003), quais sentidos, corpos e gêneros são constituídos quando essas mulheres protagonizam esses desenrolos? Como se moralizam, performam e impactam os sujeitos que com elas mantêm essas transações?

O desenrolo, portanto, não é restrito aos "homens", mas aos modos como sujeitos se autorizam (são autorizados) nessas dinâmicas de prestígio, relações e eventos que, podemos considerar, dotam de "masculino" aqueles que recorrem a ele por isso destaquei anteriormente o fato de o casal "ter sido levado" para (e não ter procurado pelo) o desenrolo. Aqui, no entanto, há outra dimensão a ser enfatizada, mas sem a intenção de refletir para além desse caso. Desde o início, o casal vítima da violência vinha tendo a sua defesa prejudicada no desenrolo, dado a ausência de poder naquela correlação de forças. Ao contrário do vizinho denunciante que era morador da favela e que parecia ter algum tipo de proximidade com os traficantes, além dos próprios atributos que ali definiam gênero e o colocavam em uma situação mais confortável. A classificação moralizante (em que gênero é um elemento central) que se produzia ali desfavorecia Cláudio e Guilherme desde o início. Isso, no entanto, se modificou quando uma relação prestigiosa, de rede de contatos, é revelada por Cláudio ao recorrer a Rogério para intervir em seu favor. Essa relação anterior entre eles, e a possibilidade de acioná-la, resultará em uma reinscrição desses corpos em um plano mais digno, humano; eles passam a importar (Butler, 2011).

Esse movimento, acredito, pode ser reconhecido na agressão que segue a intervenção de Rogério. O "soco no peito" incorpora uma forte marcação de gênero, constituindo uma violência generificada muito específica. O peitoral, junto com os braços e o rosto, talvez seja uma das principais "partes" na

${ }^{15}$ Para saber mais sobre isso, ver, entre outros, Vianna e Farias (2011) e Leite (2008). 
apresentação de uma corporalidade pública masculina (e, consequentemente, de seu distanciamento de uma feminina). Mesmo que a violência constitua uma ação feminilizante, a sua aplicação nessa "parte do corpo" confere o reconhecimento de uma espécie de masculino naquele que é vitimado - e mais do que isso.

Ao analisar a manifestação de uma forma de violência entre mulheres adolescentes de camada popular na Argentina, Blázquez (2010) reflete sobre os modos em que classificações sociais são executadas e vivenciadas em diversas regiões daquele país. $\mathrm{O}$ "corte no rosto", o tipo de golpe executado por aquelas jovens nas redondezas das escolas públicas em que estudam, "seria uma das performances através da qual as adolescentes materializam (em) seus corpos formas de classificação social que (re)fazem performativamente gênero e classe" (Blázquez, 2010:16, tradução minha). Nesse sentido, esses atos estão fundamentados em valores hierárquicos que organizam o cotidiano dessas jovens, que são atualizados em contextos de conflito como os que analisa.

\begin{abstract}
El gesto de interrupción brusca de la interacción hiere la "cara" (Goffman, 1970) del otro y lo arroja al espacio de lo abyecto que habitan los seres que (ya) no importan. El otro es un otro que ya no se presenta como deseable para establecer el intercambio que funda lo social. Al trazar esta frontera, el "corte de rostro" establece una marca que dice y hace performativamente las clasificaciones sociales que orientan las interacciones cotidianas que se interrumpen (Blázquez, 2010:22).
\end{abstract}

Refletindo a partir de Blázquez (2010), a reação e o entendimento de Cláudio a respeito daquele contexto tornam ainda mais evidente essa perspectiva: "estufar o peito" e procurar "não mostrar fragilidade" revelam a necessidade de performar a resistência, a força, a coragem, uma certa intocabilidade/ insensibilidade e uma atividade/ação (mesmo que as condições mais imediatas pudessem ter definido, inicialmente, sua possibilidades ao redor da passividade). Nesse sentido, é oportuno 
indagar sobre os sentidos das metáforas que acionam "o peito" ou "o peitoral" entre aqueles jovens, visto que é isso que é/está colocado como objeto de disputa. "Encarar de peito aberto", "uma coisa que vem do peito", "que é do fundo do peito" e "o sujeito encarou com o peitoral exibido" são apenas algumas expressões que exemplificam a importância que, ao menos entre as masculinidades juvenis de camada popular, essa região do corpo assume como forma/espaço de moralização, de constituição de si. Ao contrário de um "dar um tapa na cara" ou "jogar na cara do outro" que produzem significados correlatos ao da vergonha, da indignidade e da humilhação, marcando o desprezo $e$ a possibilidade de descontinuidade unilateral de uma relação, aqui não há indicação do outro como algo inferior, menor ou que não importa, mas a afirmação e o reconhecimento de determinada honra, dignificada pela mediação de Rogério, o traficante com quem Cláudio estudou, mas também por sua reação diante do golpe recebido.

Ainda nessa direção, talvez seja possível pensar que uma dimensão constitutiva da violência, quando recebida, como experiência valorizada de masculinidades, seja a resiliência do vitimado. "Estufar o peito" e não demonstrar "fragilidade", ao contrário de correr, chorar ou "fechar os ombros e encolher o peito" durante o evento, é uma atitude que, inicialmente, não foi prevista/esperada pelo golpeador. Portanto, o comportamento de Claudio, mostrando-se eficaz e em desajuste às expectativas de seu ofensor, mereceu uma classificação especial: "abusado" adjetivo que constitui aquele que não "reconhece o seu lugar", mas que ao mesmo tempo pode se referir àquele que possui a capacidade, a força e a coragem de "ousar", "ultrapassar limites" e "se fazer mais/maior que o que se estabelecia/esperava dele". Cláudio pretendia trazer esse segundo sentido à narrativa.

Ao reconhecerem o peitoral como um espaço de disputa em termos de definições de moralidades, em que, como dito anteriormente, apreensões em torno de gênero são elementos fundamentais, agredi-lo e blindá-lo compõem os processos de embodiment entre os sujeitos em questão. Quais são os limites 
dessa corporalidade una que será marcada pela sequência agressão-recepção-reação performada pelos dois-corposindíviduos-agentes? Como considerar uma corporalidade que, nessa cena, marca-se não apenas pelos dois diretamente em questão, mas também pelos demais envolvidos na situação e, em último caso, a consideração de corpos singulares como não individuais, observando a leitura realizada por ambos a respeito de como, de que tipo de reação deveria ser performada por si $e$ esperada do outro a partir da localização desse outro como parte de uma coletividade mais ampla. Nesse sentido, mais uma vez, é interessante considerarmos a própria adjetivação que Cláudio recebeu - "abusado" - diante da sua disposição corporal/de gênero após o golpe ter sido desferido, revelando uma série de expectativas com relação às reações que ele deveria performar.

Concluindo essa leitura a respeito da situação de violência, é oportuno destacar que Cláudio não chorou ao longo do desenrolo, mas que não deixou de fazê-lo após o seu encerramento. É interessante observar a cena que produz e é produzida por esse choro. Cláudio, no ponto de ônibus, já estava distante dos seus oponentes e da situação que, conforme argumento, era marcada por uma disputa em termos de construção de gênero. Desse modo, a fragilidade que não deveria ser indicada naquela cena, seja por lágrimas ou outros elementos, agora pode ter lugar. É interessante notar, contudo, que esse choro não produz um sujeito frágil ou o torna feminino, pelo contrário, constrói, é um elemento que performa a indignação e a revolta da parte desse agente diante do "absurdo". Essa indignação, esse choro, o conforma como um sujeito que, mesmo ferido, permanece de alguma maneira intacto, inteiro. Ele é constitutivo de uma determinada emoção que, elaborada em diálogo como um evento "absurdo", o revela de algum modo superior, inteiro, completo e digno. Em um primeiro momento, o choro o faria, como dito popularmente, "um chorão"; mas em seguida, reforçaria a sua dignidade por mostrá-lo como "um homem atingido em sua moral, em sua honra". 
Essa narrativa, portanto, (re)construtora de uma disputa em termos de definição de um embodiment, de corpos generificados, marcados pela elasticidade de tais concepções/possibilidades, exemplificados através dos diversos trânsitos e deslocamentos dos sujeitos em um mesmo cenário interativo ou contexto, a partir de um mesmo evento, revela dimensões interessantes da produção de corporalidades e moralidades em contextos de violência.

Sobre esse aspecto, considero oportuno somar a essas considerações as reflexões de Halberstam (2005) a respeito de tempos e lugares queer, pois lança luz não apenas para a dinâmica interativa entre os sujeitos específicos, mas para a importância do espaço constituindo os campos (possíveis) de ação para aquela situação de composição de gêneros/corpos. A proposta de Halberstam é interessante não apenas para considerarmos possíveis jogos específicos de gênero naquele/daquele espaço, tornando compreensíveis certas construções, articulações e entendimentos, mas para melhor observar/refletir, em diálogo com referências que visam problematizar socialidades específicas em espaços marginais, o caráter generificado do desenrolo enquanto instância fundamental de tratamento de conflitos em favelas cariocas. Dinâmicas específicas de construção de si e de evitação e relação com conflitos estão articuladas, desse modo, a espaços específicos. Aqui, mais uma vez, podemos observar a consideração do corpo individual não apenas em si, ou dado por situações específicas, contextuais, mas também em termos de corpos coletivos, sociais, orientados por dinâmicas que também podemos considerar de uma ordem social para além da contextual, interacional, entre os sujeitos.

\section{Notas finais}

De modo análogo, mas oposto de Das (1999; 2007; 2008), que a partir do caso indiano lançou luz para o "trabalho do tempo" em articulação com uma linguagem metafórica sustentada no silêncio ou em uma espécie de comportamento resignado 
como meio de se relacionar com a Partição e suas consequências, aqui, considerando não em termos de Estado ou sociedade, mas em seu caráter mais individual e de um coletivo reduzido, podemos reconhecer outro modo de inscrever, de retomar essa violência no cotidiano daqueles jovens: através do oposto, da produção de intensas e recorrentes narrativas a respeito das situações vivenciadas, com gargalhadas e em situações públicas, como na mesa de bar onde a ouvi pela primeira vez.

Sobre esse aspecto, é interessante observarmos como Das (2011) caracteriza parte de seu universo de investigação, os modos de atuação das mulheres diante das violências sofridas e o que, para ela, deve ser um dos fundamentos de nossa compreensão:

Precisamos perguntar não só como a violência étnica ou comunal foi perpetrada por atos de violação específicos de gênero, como o estupro, mas também como as mulheres tomaram esses signos nocivos de violação e os re-ocuparam através do trabalho de domesticação, ritualização e renarração. (...) As mulheres falavam de suas experiências ancorando seus discursos nos gêneros do luto e da lamentação que já lhes atribuíam um lugar no trabalho cultural do luto, mas elas falavam da violência e da dor tanto dentro desses gêneros como fora deles (Das, 2011:11).

Essas estratégias constituíram os meios que as informantes de Das (2011) e seus pares forjaram para lidar com a violência e os seus efeitos de produção de "conhecimento venenoso". Como destacado no trecho citado acima, há um trabalho de domesticação, ritualização e re-narração da violência que tem como consequência o controle do "veneno" trazido pela lembrança/existência do evento ocorrido no passado, mas rememorado ( $e$, portanto, construído novamente) no presente. $\mathrm{O}$ passado e o presente não constituem, portanto, tempos afastados, apartados, em que um concederia espaço ao outro, mas uma ponte sempre acionada na experiência desses sujeitos em seu 
cotidiano. $\mathrm{O}$ ato de testemunhar, portanto, como "uma maneira de entender a relação entre violência e subjetividade", será o ponto de partida para a autora refletir sobre os modos como aquela relação se inscreve no cotidiano $e$, junto com isso, nas trajetórias dos sujeitos.

Seguindo essa perspectiva, devemos considerar o aspecto performático da própria narrativa em termos de construção de corpos/corporalidades e de gênero. Das (1999) argumentará, do mesmo modo, sobre a especificidade de certos aspectos na construção das histórias de mulheres que "preferiram a morte à desonra" no contexto da Partição como formas de (re)inscrição dessas violências no cotidiano:

Essas histórias enquadram a violência de modo a torná-la assimilável à experimentação da cultura com os limites da experiência humana. Mesmo diante da morte horrenda, os homens sabem como se comportar de acordo com as normas da masculinidade; as mulheres sabem o que é preciso fazer para preservar a honra de seus homens (Das, 1999:37).

Como pretendi explicitar na seção em que analisei as dinâmicas de gênero constituídas na cena, tal qual relatada por Cláudio, há uma clara demarcação de corpos e gênero na leitura que ele apresenta sobre as razões e o modo como aquele ato violento foi se realizando. Nesse sentido, a violência narrada realiza um trabalho sistemático de constituição de Cláudio como masculino, corajoso, forte e honrado, revelando-se um meio eficaz de inverter a correlação de forças disposta durante o evento. Assim, retomando outro argumento de Das, existem algumas violências que por atentarem "contra a natureza" e definirem "limites da própria vida" não devem ser ditas/lembradas/recusadas, mas, é possível sugerir que, outras tantas gozam de autorização especial dado o seu potencial performativo com relação a constituição de sujeitos morais. Revelar esses eventos, isto é, produzir determinadas narrativas, reconhecendo gramáticas específicas, constitui um modo de 
domesticar os eventos passados e, de algum modo, forjar algum controle sobre as possibilidades cotidianas, do presente, de eles virem à tona (como fatos ocorridos ou como novos eventos possíveis). E é isso que Cláudio e seus amigos, ao narrarem o evento que, como ele chamou, é "absurdo", mas, ao mesmo tempo, próximo e previsível em seus cotidianos, também fazem enquanto dão as suas gargalhadas e tomam cerveja em bares.

Ao longo de todo o meu trabalho de campo, como ocorreu com relação ao evento que trouxe aqui, quase toda breve conversa com um possível interlocutor sobre meu interesse de pesquisa suscitava, de imediato, a referência a algum evento envolvendo uma reação negativa do tráfico em direção a indivíduos não heterossexuais. Eram relatos que aconteciam com as próprias pessoas, amigos, conhecidos ou mesmo constituíam apenas narrativas que permitem perceber o medo que seus agentes despertavam nesses sujeitos. Esse foi um tema que, ao longo da pesquisa e da escrita me perturbou, pois eu me preocupava em, de algum modo, ao trazer os relatos sobre violência que ocorriam na favela de onde partia a minha pesquisa, reforçar uma série de estigmas que costumam incidir sobre esses territórios (associação com o "crime", a "barbárie", a "violência" etc.). As violências ocorriam, mas os meus interlocutores faziam mais do que simplesmente contarem o que aconteceu. Eles construíam e davam significado às coisas.

No enfrentamento dessas questões, a proposta de "crítica à violência" de Benjamin (2013) permite olhar para esse fenômeno de outro modo, viabilizando que se fuja de uma perspectiva meramente apreciativa em torno da gravidade dos meios ou ainda da qualidade do fim, para compreender esses atos em sua natureza sócio-antropológica, como instauradores de moralidades, relações e sentidos. Foi seguindo essa direção que procurei mostrar que a violência, conformada por uma série de constructos de gênero compartilhados por aqueles e tantos outros jovens moradores de favelas no Rio de Janeiro, é concebida/construída por uma tentativa de subjulgar o outro, considerando aspectos que, no interior daquelas socialidades, são feminizantes. A análise 
cadernos pagu (55), 2019:e195520 Corpos, gêneros e subjetividades em disputa

desse caso, portanto, nos leva a crer, como destacado na própria epígrafe deste artigo, no caráter fundamentalmente generificado da violência.

\section{Referências bibliográficas}

ABU-LugHOD, Lila. Veiled Sentiments: Honour and Poetry in a Bedouin Society. Berkeley, University of California Press, 1988

BENJAMIN, Walter. Escritos sobre mito e linguagem (1915-1921). Organização, apresentação e notas de Jeanne Marie Gagnebin. São Paulo, Duas Cidades; Editora 34, 2013.

BLÁZQUEZ, Gustavo. De cara a la violencia. Agresiones físicas y formas de clasificación social entre mujeres jóvenes de sectores populares en Argentina. Sexualidad, Salud y Sociedad - Revista Latinoamericana. n 6, Dec 2010 [http://www.scielo.br/pdf/sess/n6/a02n6.pdf - acesso em: 05 dez. 2016].

ButLen, Judith. Problemas de Gênero: feminismo e subversão da identidade. Rio de Janeiro, Civilização Brasileira, 2.ed., 2008.

BUTLER, Judith. Bodies that matter. On the Discursive Limits of "Sex". New York, Routledge, 2011. [1993]

Collier, Jane; YANAGISAKO, Sylvia J. Gender and Kinship: essays towards a unified analisys. Stanford, Stanford Un. Press, 1987.

CSORDAS, T. The body's career in Anthropology. In: MoORE, H. (ed.), Anthropological Theory Today. Cambridge, Polity Press, 1999, pp.172-205.

DAS, Veena. Fronteiras, violência e o trabalho do tempo: alguns temas wittgensteinianos. Rev. Bras. C. Soc., vol. 14, n 40, São Paulo, jun. 1999 [http://www.scielo.br/scielo.php?script=sci_arttext\&pid=S010269091999000200003\&lng $=e n \& n r m=$ iso - acesso em: 02 fev.2017].

DAS, Veena. Life and Words: Violence and the descent into the ordinary. Berkeley, University of California Press, 2007.

DAS, Veena. Violence, Gender and Subjectivity. Annual Review of Anthropology, 37, 2008, pp.283-99. 
DAS, Veena. O ato de testemunhar: violência, gênero e subjetividade. cadernos pagu (37), Campinas, Núcleo de Estudos de GêneroPagu/Unicamp, 2011 [http://www.scielo.br/pdf/cpa/n37/a02n37.pdf acesso em 20 jan. 2017].

DiAS-BEnITEZ, María Elvira. Nas redes do sexo: bastidores do pornô brasileiro. Rio de Janeiro, Jorge Zahar, 2010.

FAusto-Sterling, Anne. Sexing the body: gender politics and the construction of sexuality, New York, Basic Books, 2000.

FouCAult, Michel. História da sexualidade I: a vontade de saber. São Paulo, Graal, 1984.

GREGORI, Maria Filomena. Cenas e queixas: Um estudo sobre mulheres, reações violentas e práticas feministas. São Paulo, ANPOCS $\backslash \mathrm{Paz} e$ Terra, 1993.

HAlBeRSTAM, J. In a Queer Time and Place: Trangender bodies, subcultural lives. Nova Iorque, NYU Press, 2005.

HaRAWAy, Donna. Primate Visions: Gender, race and nature in the world of modern science. New York, Routledge, 1989.

LEITE, Márcia da Silva Pereira. Violência, risco e sociabilidade nas margens da cidade: percepções e formas de ação de moradores de favelas cariocas. In: MACHADO DA SILVA, Luiz Antonio (org.). Vida sob cerco: violências e rotinas nas favelas do Rio de Janeiro. Rio de Janeiro, Nova Fronterira, 2008, pp.115-142.

LOPES, Paulo Victor Leite. Sexualidade e construção de si em uma favela carioca: pertencimentos, identidades, movimento. Dissertação (Mestrado em Antropologia Social) - Museu Nacional, Universidade Federal do Rio de Janeiro, Rio de Janeiro, 2011.

MACHADO DA SILVA, Luiz Antonio (org.). Vida sob cerco: violências e rotinas nas favelas do Rio de Janeiro. Rio de Janeiro, Nova Fronteira, 2008.

MATTOS, Carla dos Santos. Viver nas margens: gênero, crime e regulação de conflitos. Tese (Doutorado em Ciências Sociais), Universidade do Estado do Rio de Janeiro, 2014. 
cadernos pagu (55), 2019:e195520 Corpos, gêneros e subjetividades em disputa

MCCLINTOCK, Anne. Couro Imperial. Raça, travestismo e o culto da domesticidade. cadernos pagu (20), Campinas, Núcleo de Estudos de Gênero-Pagu/Unicamp, 2003, pp.7-85.

MOORE, Henrietta. Fantasias de poder e fantasias de identidade: gênero, raça e violência. cadernos pagu (14), Campinas, Núcleo de Estudos de Gênero-Pagu/Unicamp, 2000, pp.13-44.

RUBIN, Gayle. The Traffic in Women. Notes on the "Political Economy" of Sex. In: ReITER, Rayna (ed). Toward an Anthropology of Women. New York, Monthly Review Press, 1975, pp.157-210.

STOLER, Ann Laura. Sexual affronts and racial frontiers: European identities and the cultural politics of exclusion in Colonial Southeast Asia. In: COOPER, Frederick; STOLER, Ann Laura (ed.). Tensions of Empire: Colonial Cultures in a Bourgeois World. Berkeley, University of California Press, 1997, pp.198-237.

STRATHERn, Marilyn. O Gênero da Dádiva: Problemas com as mulheres e problemas com a sociedade na Polinésia. Campinas, Ed. Unicamp, 2006.

VIANNA, Adriana; FARIAS, Juliana. A guerra das mães: dor e política em situações de violência institucional. cadernos pagu (37), Campinas, Núcleo de Estudos de Gênero-Pagu/Unicamp, dez. 2011 [http://www.scielo.br/pdf/cpa/n37/a04n37.pdf - acesso em: 27 set. 2016].

YANAGISAKO, Sylvia; COLLIER, Jane. Toward a unified analysis of gender and kinship. In: YANAGISAKO, S.; COLliER, J. (ed.). Gender and Kinship: essays toward an unified analysis. Stanford, Stanford University Press, 1987, pp.14-52. 